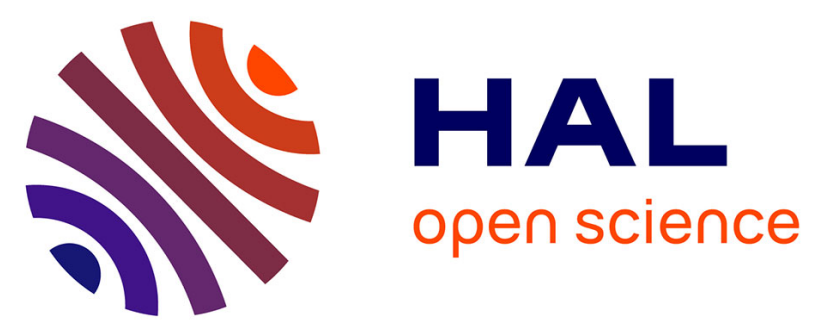

\title{
Mobile phones in the spread of unreliable information on Twitter: evidence from the 2017 French presidential campaign
}

\author{
Julien Figeac, Pierre Ratinaud, Nikos Smyrnaios, Guillaume Cabanac, \\ Ophélie Fraisier, Tristan Salord, Fanny Seffusatti
}

\section{To cite this version:}

Julien Figeac, Pierre Ratinaud, Nikos Smyrnaios, Guillaume Cabanac, Ophélie Fraisier, et al.. Mobile phones in the spread of unreliable information on Twitter: evidence from the 2017 French presidential campaign. Mobile Media \& Communication, 2021, 9 (3), pp.441-464. 10.1177/2050157920972157 . halshs-03049810

\section{HAL Id: halshs-03049810 \\ https://shs.hal.science/halshs-03049810}

Submitted on 2 Dec 2021

HAL is a multi-disciplinary open access archive for the deposit and dissemination of scientific research documents, whether they are published or not. The documents may come from teaching and research institutions in France or abroad, or from public or private research centers.
L'archive ouverte pluridisciplinaire HAL, est destinée au dépôt et à la diffusion de documents scientifiques de niveau recherche, publiés ou non, émanant des établissements d'enseignement et de recherche français ou étrangers, des laboratoires publics ou privés. 


\title{
Mobile phones in the spread of unreliable information on Twitter: Evidence from the 2017 French presidential campaign.
}

\author{
Version des auteurs
}

Julien Figeac

French National Center For Scientific Research

Corresponding author: Julien.figeac@cnrs.fr

Pierre, Ratinaud

LERASS - University of Toulouse III

Nikos, Smyrnaios

LERASS - University of Toulouse III

Guillaume, Cabanac

IRIT - University of Toulouse III

Ophélie, Fraisier

IRIT - University of Toulouse III

Tristan, Salord

IRIT - University of Toulouse III

Fanny, Seffusatti

LISST - University of Toulouse II

\section{Reference :}

Julien Figeac, Pierre Ratinaud, Nikos Smyrnaios, Guillaume Cabanac, Ophélie Fraisier, Trsitan Salord, Fanny Seffusatti, Mobile phones in the spread of unreliable information on Twitter: evidence from the 2017 French presidential campaign. Mobile Media \& Communication, 2021, 9 (3), pp.441-464. 


\begin{abstract}
This article analyzes the spread of unreliable information on Twitter during the 2017 French presidential campaign, focusing on the use of mobile phones with regard to information-sharing behavior. The corpus is composed of 38,346,765 tweets, posted by 2,163,812 supporters of the five main French political parties, from November 25th, 2016 to May 12th, 2017. We examine more precisely a sub-corpus of tweets $(13,044,619)$ containing links to external information sources, in order to evaluate the different types of information sources and their reliability.

Our research shows that information-sharing behavior within Twitter in France is generally based on reliable information sources, produced by journalists and professional media. However, we highlight that smartphone users tended to share a greater amount of usergenerated content, as well as articles from a wider range of alternative political information sources (blogs, activists' websites); such sources were most likely to publish unreliable information. Thus it appears that users of mobile phones tend to share more unreliable news than those who use Twitter from a computer web browser. Further, we show that this "device effect" on the spread of unreliable information is primarily amplified among the practices of one political community - namely, the far-right party and its network of supporters - which is more likely to organize debate around a larger number of unreliable references. We are claiming here that the design-based interoperability of these unreliable political news and social media applications helps to understand why the French far-right community shared more unreliable information from the Twitter application.
\end{abstract}

Keywords: Social Media, Political Participation, Mobile Phone, Information Sharing, Fake News. 


\section{Mobile phones in the spread of unreliable information on Twitter: Evidence from the 2017 French presidential campaign.}

The effects of the Internet and social media on the democratic balance of societies at large fuel a paradox. On the one hand, current literature tends to highlight the revitalizing effects of the Internet on democracy, insofar as it provides a platform for debate (Shane, 2004) and generates a wealth of information favorable to the forming of enlightened opinions, facilitating exposure to a wider range of ideas (Benkler, 2006). Many scholars show how the use of social media thus encourages information sharing and political participation (Boulianne, 2015; Koc-Michalska, Lilleker and Vedel, 2016). However, there are drawbacks to this new way of engaging with news and politics (Valenzuela et al., 2019): The enhancement of citizen participation brought about by social media is linked to - and even amplifies - the spread of disinformation. We wish to explore the various dimensions of this paradox by analyzing more precisely the specific role of mobile phones in political participation and in information-sharing behavior, in order to determine whether such devices can foster the spread of unreliable information during political campaigns to a greater extent than others.

It is well known that mobile phones have brought about increasingly important changes in public life, and the way in which individuals participate in politics (Kwak et al., 2011; Martin, 2014). Mobile phones are often and effectively the preferred mode of communication for political activists, particularly during demonstrations and protests (Neumayer and Stald, 2014), as such citizens seldom have access to desktop computers when they are involved in the processes of street-level activism. When focusing on the way information and communication technologies (ICT) can promote political participation, the question of technological "affordances", or, "the actions a given technology - such as social media apps - facilitates or makes possible" (Tufekci, 2017), becomes increasingly relevant. 
These technological devices afford users the opportunity to participate in social media at any time. Thus we need to better understand how such opportunities may transform the democratic debate, as well as the ways in which mobile phones can promote the spread of unreliable information. Drawing on previous work which shows that the "fake news" audience on mobile phones is a "niche" group primarily composed of disloyal community members (Nelson, Taneja, 2018), we pursue this research in order to better highlight what is unique about mobile media as a space for sharing political information and opinions (Campbell \& Kwak, 2011; Martin, 2014). We shall target here the uses of Twitter and the role played by devices used to consult this service - notably smartphones - in regard to unreliable information-sharing behavior. Does the use of the Twitter mobile application favor the spread of false or unreliable information? Or, on the contrary, are desktop-based Twitter uses more likely to relay unreliable information? We consequently propose to evaluate whether those users who shared unreliable information during the 2017 French presidential campaign were more likely to access Twitter via a smartphone or a desktop computer.

After introducing our hypotheses and method, we present our results in two parts. First, we analyze the data relating to sharing behavior from various types of information sources (press, political sites, personal pages, and so on) on Twitter, in order to assess how reliable, professionally-produced information is today countered by an abundance of additional material exchanged on the social media service. In the second section, we evaluate the proportions of "reliable" and "unreliable" information sources shared among the main French political communities. Our objective is to measure whether the number of reliable and unreliable information sources varies according to the political community, and to determine if such variation differs depending on the user's means of access to the Twitter platform: either the mobile application or the browser-based website. 


\section{The spread of unreliable information within the French political communities}

The spread of disinformation and so-called "fake news" has emerged as a prominent public issue, especially in Europe (Neudert, Howard and Kollanyi, 2019). Despite numerous references to "fake news" in the general media, the notion is overused and often misused (Tandoc, Lim and Ling, 2017). Faced with the diversity of uses of the "fake news" tag, scholars have identified the methodological challenges of using such terminology and have developed a precise typology for studying the spread of "junk news" (Neudert, Howard and Kollanyi, 2019). This typology is based on the domain names of information sources shared on Twitter, and is used to code, among other things, the professionalism and degree to which such sources are highly biased or ideologically driven. The goal is to identify such sources of “junk news", in order to distinguish them from other types of information sources from which articles have been shared in Twitter during political elections; in particular, from “professional news sources", "professional political sources", or "other political news and information sources" shared by citizens within civic society.

In this research, we reproduced and developed this typology in order to study the spread of unreliable information on mobile devices during the 2017 French presidential campaign. As the term "junk news" seems to have too many negative connotations, we used the label unreliable information in designating different types of unreliable information sources, specifically those which have already been found to publish or share misinformation (for example, various citizen-journalist websites, partisan blogs and activist websites). We know that mobile phones provide new channels of communication for citizens, particularly during demonstrations and protests (Neumayer and Stald, 2014). We also know that some of the information sources shared by such users might not necessarily be considered "alternative", since professional reporters will occasionally contribute to them in addition to their primary outlets (Goode, 2009). For this reason, we have coded such news sources as 
“other political news and information" (Neudert, Howard and Kollanyi, 2019), distinguishing in a second step between the reliable and the unreliable. In order to identify these unreliable sources, we used a fact checking database ${ }^{1}$ that references most of these other sources; this database also allowed us to distinguish reliable sources of information, in particular "professional news sources".

Scholars have demonstrated that the audience for these unreliable sources is far smaller than the audience for professionally-produced media information (Nelson and Taneja, 2018): They represent less than 1\% of the "civic" content published via Facebook (Weedon, Nuland and Stamos, 2017). But studies have also shown how this audience varies from one political community to another, depending on the political beliefs of their members. In the United States, for example, the spread of disinformation on Twitter (Guess, Nagler and Tucker, 2019) and Facebook (Grinberg et al., 2019) is largely seen among individuals with the strongest political convictions. In other countries, as well, certain political communities are more likely than others to share more unreliable information, such as the partisans of Bolsonaro in Brazil (Machado et al., 2018) or, in India, the supporters of the Bharatiya Janata Party (BJP) and the Indian National Congress (Narayanan et al. 2019). The same phenomenon can be observed in France, because the right-wing (Les Républicains, or LR) and far-right (Front National, or $F N$ ) partisans tend to share more unreliable information on Twitter than others (Gaumont, Panahi and Chavalarias, 2018). In this research we therefore expand on these previous works, which deal with the spread of unreliable information, by highlighting possible differences between political communities (Figeac et al., 2020).

\footnotetext{
${ }^{1}$ Cf. Décodex site: https://www.lemonde.fr/verification/.
} 


\section{Mobile communication and the spread of unreliable information}

Research on the spread of unreliable information systematically downplays, and even ignores, the importance of devices (smartphones or computers) or modes of access (mobile applications or browser-based websites). Taking into account forms of technological support in the spread of fake news is nonetheless important, because it is now established that users consult Internet services with their mobile applications increasingly often. We know that smartphones and mobile news apps tend to be used more and more by individuals when engaged in information-gathering and -sharing practices (Westlund, 2015), especially during election campaigns (Martin, 2015), or when consulting social media (Smith and Page, 2015). This is also the case in France. As of 2018, French citizens most often consult news websites $(56 \%)$ and Twitter $(54.7 \%)$ via their mobile phones ${ }^{2}$. However, during the presidential campaign in 2017 , they still favored the use of computers: at that time, $43.7 \%$ of French used their mobiles phones to access news ${ }^{3}$ or to consult Twitter. Even if these data lead us to expect an over-representation of computer based information-sharing behavior in our results, their analysis is important in better understanding whether peripatetic use of these applications can influence information-sharing behavior, and more precisely, whether these mobile services can make users more inclined to (re)tweet unreliable sources.

Nelson and Taneja (2018) analyzed the audiences for unreliable information through this perspective. They found that, despite the fact that time spent on unreliable news sites was lower than time spent on trustworthy news sites, it appeared that visitors were significantly more likely to encounter unreliable news sites by clicking a link on Facebook, especially when using the mobile application. We might expect here the same pattern with respect to the

\footnotetext{
${ }^{2}$ Médiamétrie, Audience Internet Global en France, novembre 2018. Retrieved from < https://www.mediametrie.fr/sites/default/files/2019-01/2019\%2001\%2003\%20$\%$ 20CP\%20Audience\%20Internet\%20Global_Novembre2018.pdf > ${ }^{3}$ Ibid.
} 
Twitter app. These results extend the experimental research of Vishwanath (2016), who showed that individuals are increasingly liable to fall victim to phishing attacks because of the affordances of smartphones. The detection of malicious content and, more generally, the “cognitive, affective, and behavioral trust (...), regardless of the content of information and the modalities through which the information is delivered" varies according to certain smartphone affordances, such as screen size (large vs. small) and modes of presentation (video vs. text) (Kim \& Sundar, 2016). We could expect here that the effects of these affordances on information-sharing behavior are all the more germane to the Twitter app.

Here we extend these findings by considering that smartphone affordances may also have an impact on unreliable information dissemination on Twitter. More specifically, we defend the idea that Twitter "Share" buttons are the primary affordances relating to such information-sharing behavior. Indeed, the "Share" buttons featured on most websites play an essential role in information sharing through social media (Langlois \& Elmer, 2013). By facilitating the sharing of content between websites and social media, these buttons are affordances that signal a function-action link and tend to promote information sharing. These buttons are an evolution of the hyperlink: They make information accessible and help to establish information networks, creating paths that link social media platforms to the rest of the Internet. Mobile websites and applications are designed around this interoperability, displaying "Share" buttons in conspicuous areas to encourage users to pass along content through social media. For small-sized mobile phones, these buttons are placed in highly visible areas of application interfaces or of mobile versions of websites. We thus hypothesize here that users are more likely to share content when using smartphones (via these highly visible buttons) compared to when using web browsers. As these buttons play a more important function with respect to information-sharing patterns on mobile phones, we argue here that they help to understand why users are more likely to share more unreliable 
information from the mobile application of Twitter. And, as the size of smartphone screens influences users' disposition to trust malicious information (Kim and Sundar, 2016), we consider that this smartphone affordance can also lead users to share more unreliable information in social media using the Twitter "Share" button.

\section{Hypotheses}

In this article, we therefore extend previous work (Nelson and Taneja, 2018) by analyzing the proportion of reliable versus unreliable sources that were shared on Twitter during the 2017 presidential campaign in France. We distinguish the audiences for these two types of information according to whether they used the mobile Twitter application, or whether they used a web browser. This allowed us to test our first hypothesis (H1):

\section{H1. Twitter users connecting to the service via mobile applications share more} content from unreliable sources than those connecting via desktop.

During the 2017 presidential campaign, fact-checking journalists and scholars identified the ways in which producers of false information attempted to influence debate in France. They revealed numerous examples of disinformation in social media before focusing on the role of "alternative" information sources (Haski, 2017). In this context, journalists from the national newspaper Le Monde created the Décodex ${ }^{4}$, an online fact-checking platform, in order to reference these "other political news and information" sources (Neudert, Howard and Kollanyi, 2019), identifying those considered unreliable. We analyzed the sharing of these "other" sources of information in order to determine the role of mobile phones (H2):

\footnotetext{
${ }^{4}$ Cf. Décodex site: https://www.lemonde.fr/verification/
} 
H2. Twitter users connecting to the service via mobile applications share more content from other political news and information sources than those connecting via desktop.

We have concluded the previous section by highlighting the importance of the different political communities in the spread of unreliable information (Figeac et al., 2020). This is especially the case in France, where disinformation is effectively more prevalent on Twitter among right-wing and far-right supporters (Gaumont, Panahi and Chavalarias, 2018). After having evaluated whether the spread of "unreliable" and "other political news and information" sources is more strongly associated with the use of the Twitter mobile application (H1 and $\mathrm{H} 2$ ), we shall look at the apparent differences between the main French political communities by analyzing if some such groups tend to share more content from unreliable sources via mobile phones than others. Following Gaumont et al. findings (2018), we can expect an overrepresentation of right-wing and far-right political communities in this regard.

\section{Method}

\subsection{Method used to detect the political communities}

In order to study the circulation of unreliable information on Twitter during the French presidential campaign, we collected a large corpus of tweets based on a list of keywords and official hashtags relating to the leading electoral candidates. This study focused on the five predominant French political communities, which supported the candidatures of: Jean-Luc Mélenchon, the leader of "La France Insoumise” (LFI), which is a political movement bringing together various political forces of the radical far-left; Benoît Hamon, who represented the French "Parti Socialiste" (PS) and the moderate left; Emmanuel Macron, the eventual winner of the election, who unified the centrist political movement by creating the 
party "La République En Marche" (REM); François Fillon, who led the right-wing party "Les Républicains" (LR); and Marine Le Pen, the leader of the far-right "Front National" (FN), a growing political movement in France that is very active on Twitter. We retrieved the tweets relating to these five candidates posted between November 25, 2016 and May 12, 2017, the latter being five days after Emmanuel Macron won the election.

The tweet corpus is composed of $38,346,765$ tweets, posted by $2,163,812$ different accounts (cf. Fraisier et $a l ., 2018$ ). We analyzed the underlying graph of retweets to discern political communities therein, so as to analyze the sharing of unreliable sources within the various political communities. To reach this goal, we reproduced a method to identify political communities on Twitter that combines an automatic online community detection method with a qualitative community detection method performed by political media experts (cf. Smyrnaios and Ratinaud, 2017).

The first step consisted in applying the Louvain algorithm implemented in the Gephi software to the mentions and retweets graph. This step grouped the Twitter accounts that mentioned and retweeted each other several times. We were then able to manually and qualitatively identify the resultant clusters as political communities, based on the groups of Twitter accounts that were aggregated by the algorithm. For example, we identified the "PS" political community by identifying the group of Twitter accounts centered around the candidate Benoît Hamon, and other leaders of the Parti Socialiste.

To control the result of this double categorization (automatic and manual), we manually checked 22,853 Twitter profiles within this corpus in order to determine if they had been categorized in the appropriate political community. (This dataset paper describes a detailed analysis of our corpus and how we have categorized French political communities, cf. Reference to a dataset paper published by the author). 


\subsection{Categorizing the types of contents and their reliability}

After identifying the five main political communities that used Twitter during the 2017 French presidential campaign, we had to identify the type of sources they shared in order to analyze the spread of unreliable information (H1), and the sharing of "other" political news sources (H2). It appeared that only one-third of the tweets and retweets (30.82\%; cf. Figure 1) contained one or more URLs to pages of external information sources ${ }^{5}$. In this article, we analyze only this sub-corpus of (re)tweets $(n=13,044,619)$.

Figure 1. Breakdown of the different types of content within tweets and retweets

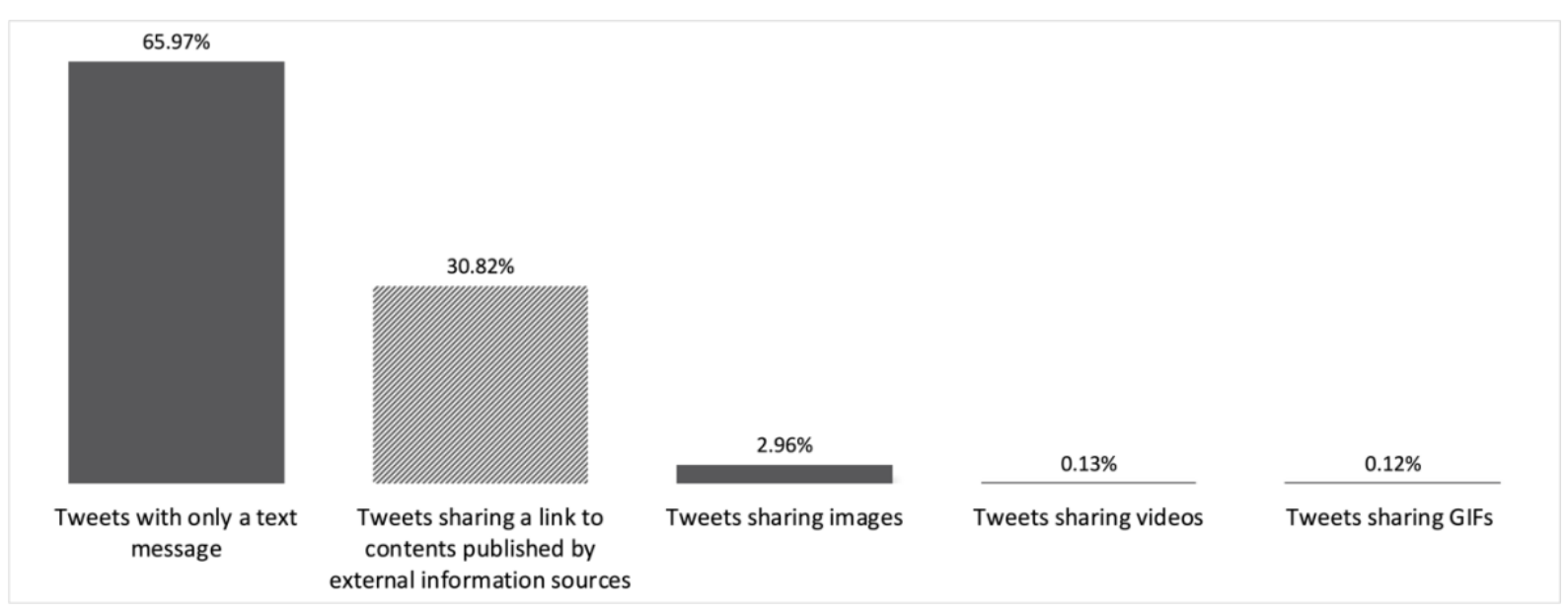

Since these tweets contained thousands of links, the first objective of this research consisted in identifying the main types of information sources that were shared: news articles, polls, YouTube videos, supporters' posts, etc. The second objective was to determine the reliability of these sources.

In determining such reliability, researchers typically use data from fact-checking sites and the thousands of examples of false information identified therein (Vosoughi, Roy and Aral, 2018). For our research we used the Décodex, a French database that was developed by

\footnotetext{
${ }^{5}$ Figure 1 references only the photos $(2.96 \%)$ and videos $(0.13 \%)$ that users directly published. Videos retweeted from another platform, such as YouTube or Dailymotion, are not referenced here. When presenting the results later, these videos appear under the category "Social Media."
} 
reporters working for the daily newspaper Le Monde $e^{6}$ (Figueira and Oliveira, 2017). Décodex references the main French-language news sources and classifies them according to their reliability. It identifies and distinguishes reliable sources, which carry out the real journalistic work of verification, from those that are unreliable or hardly reliable, and which are known to have relayed misinformation or disinformation in the past. Décodex is released as a downloadable database referencing the domain names of different information sources by classifying them as "reliable" or "unreliable", and further by type (newspapers, TV channels, news websites, etc.). Some types of sources were not listed in Décodex: political party websites, NGOs, associations, polling organizations, access providers (Orange, SFR, Free, etc.), data-sharing platforms (Dropbox, etc.). We complemented the coding of these "other political news and information" sources alongside blogs and nonprofessional media included in the Décodex database, identifying their reliability when possible. This manual classification allowed us to fine-tune our analysis of the diversity and reliability of information sources shared by the different political communities.

\subsection{Platform identification}

After having identified the various political communities, and classifying the information sources they shared according to their reliability and type, we had to identify the platforms used to publish the tweets and retweets by differentiating the uses of the Twitter mobile application from those on web platforms.

The data provided by Twitter allowed us to identify a large number of different platforms ("Twitter for iPhone", “Twitter for web client", etc.). We classified them into two categories: 1) "Mobile OS” (Mobile Operating System) for Twitter used on mobile devices

\footnotetext{
${ }^{6}$ Cf. Décodex site: https://www.lemonde.fr/verification/
} 
and 2) "Non-Mobile OS" for Twitter used from a web browser on a computer. Even if the uses of tablet devices, such as the iPad, differ from those of smartphones, we opted for including them in the category of mobile devices (Mobile OS), since they are based on comparable operating systems and their contexts of use are often the same; for example, mobile phones are used frequently to check users' Twitter timelines from home. This methodological choice is also based on the limited number of tweets published from tablet devices $(2.75 \%$; 446,299 tweets) and the fact that previous work does not differentiate them from other mobile platforms (Nelson and Taneja, 2018).

Finally, we coded $11,048,901$ tweets among those in our corpus that contained a link to one or more information sources $(13,044,619)$. More specifically, we identified the different types of information sources that were shared from the Twitter mobile application (46.99\%; Table 1) or web browser (53.01\%). Note, these scores correspond to the uses of Twitter in 2017, when $43.7 \%$ of French individuals used their mobiles phones and $56.3 \%$ used a web browser to access Twitter and check news websites ${ }^{7}$.

We then assessed the reliability of these sources by using the Décodex categorization: $2,063,066$ tweets were thus coded. This result is significantly lower than the previous one. As we have stated, it is not always possible to specify the reliability of a source of information, for example when it is the site of a political party or a blog. On the other hand, this score is lower because we have chosen here to retain only tweets that may have been affiliated to a political community. As it is often difficult to code the political affiliation of a Twitter account, the final detection score is relatively low. Despite this, this dataset is consistent with previous research (Neudert, Howard and Kollanyi, 2019; Gaumont, Panahi and Chavalarias, 2018) and allows us to test our hypotheses.

\footnotetext{
${ }^{7}$ Médiamétrie, Audience Internet Global en France, novembre 2018. Retrieved from <https://www.mediametrie.fr/sites/default/files/2019-01/2019\%2001\%2003\%20$\%$ 20CP\%20Audience\%20Internet\%20Global_Novembre2018.pdf >
} 
Table 1. Score of the information sources regarding the platforms and the political communities

\begin{tabular}{lrrr}
\hline & $n$ & \multicolumn{2}{c}{$\%$} \\
\cline { 3 - 4 } & & Mobile OS & Non-Mobile OS \\
\hline Types of information sources & $11,048,901$ & $46.99 \%$ & $53.01 \%$ \\
$\begin{array}{l}\text { Reliability of information sources } \\
\text { according to the political community }\end{array}$ & $2,063,066$ & $41.01 \%$ & $58.99 \%$ \\
\hline
\end{tabular}

\section{Results}

\subsection{The uses of the Twitter mobile application place reliable sources of professional media at a disadvantage}

During the 2017 French presidential campaign, Twitter users structured their exchanges around a wide variety of information sources (cf. Figure 2). First of all, we will analyze the diversity of these sources in order to understand the context of informationsharing behavior on Twitter, as well as the pluralism of information competing with reliable information published by professional media. In the next section, we will respond more directly to our research hypotheses by analyzing the proportion of unreliable sources shared from the different types of platforms (Mobile OS or Non-Mobile OS).

Globally, the majority of the links shared in our sample pointed to professional journalistic sources (labeled as Press in Figure 2). This remained a general tendency no matter what type of platform used to share reliable information on Twitter published by journalists. This being said, the collected data highlights that mobile application uses adversely affect the sharing of articles published by professional media, as the portion of these sources $(78.44 \%)$ is lower by 11 percentage points than that of those published on web platforms $(89.59 \%)$. 
Figure 2. Types of sources shared on Twitter according to the platform used

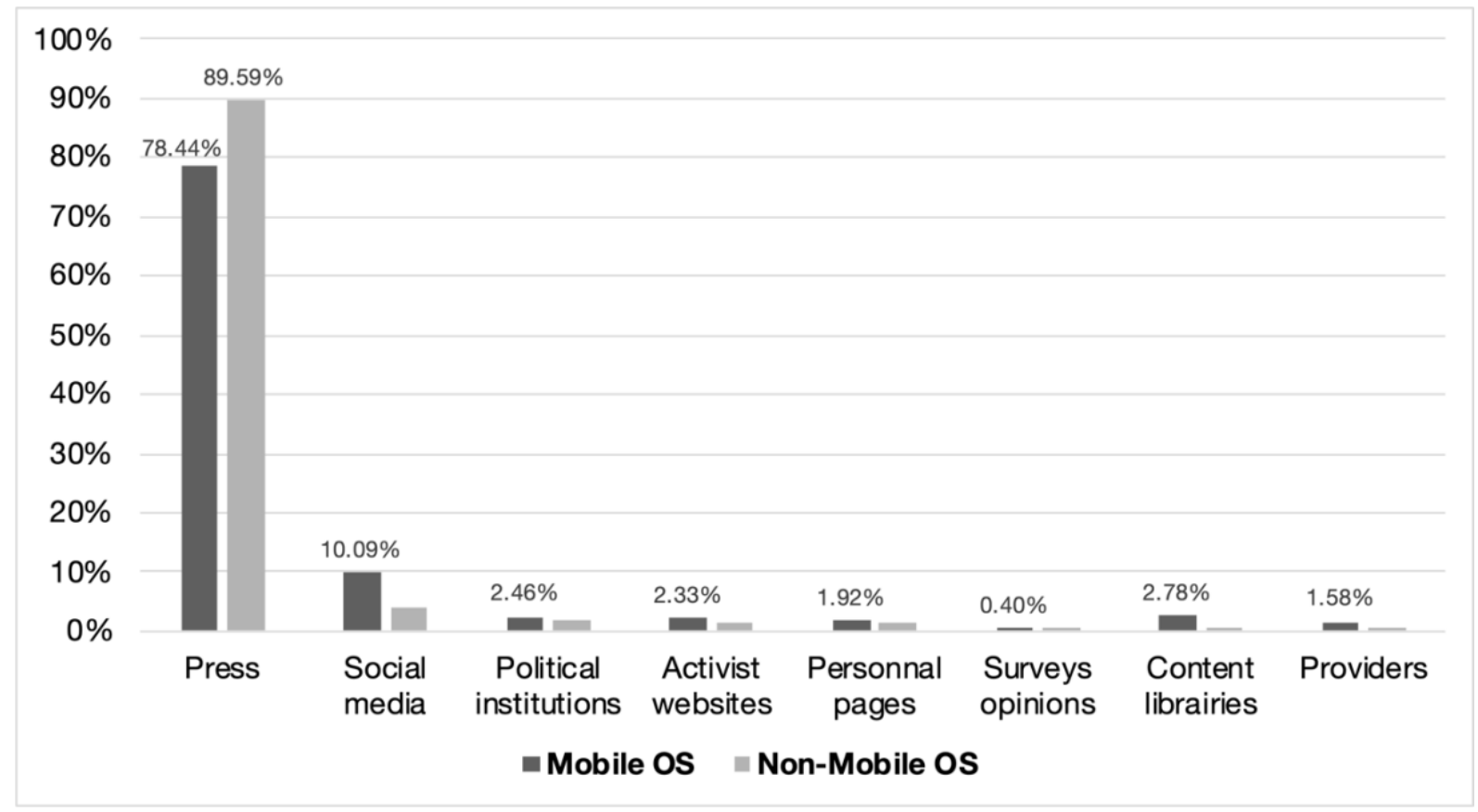

Figure 3 gives more detail regarding the sharing patterns of the different subcategories of professional media. We observe that the use of different types of platforms has no impact on the type of press shared. National newspapers are the most often cited sources, and represent approximately half of the news content that circulated on Twitter via both Mobile OS and Non-Mobile OS. A quarter of the content came from websites affiliated with television stations (particularly 24-hour news channels, national news broadcasts, and regional general-interest networks) and to a lesser degree, national radio stations. The remaining content came from magazine websites, the international or regional press, or online-only news websites ${ }^{8}$.

\footnotetext{
${ }^{8}$ It is a question here of news websites that have only a digital version on the internet.
} 
Figure 3. Breakdown of the types of press shared on Twitter according to platforms

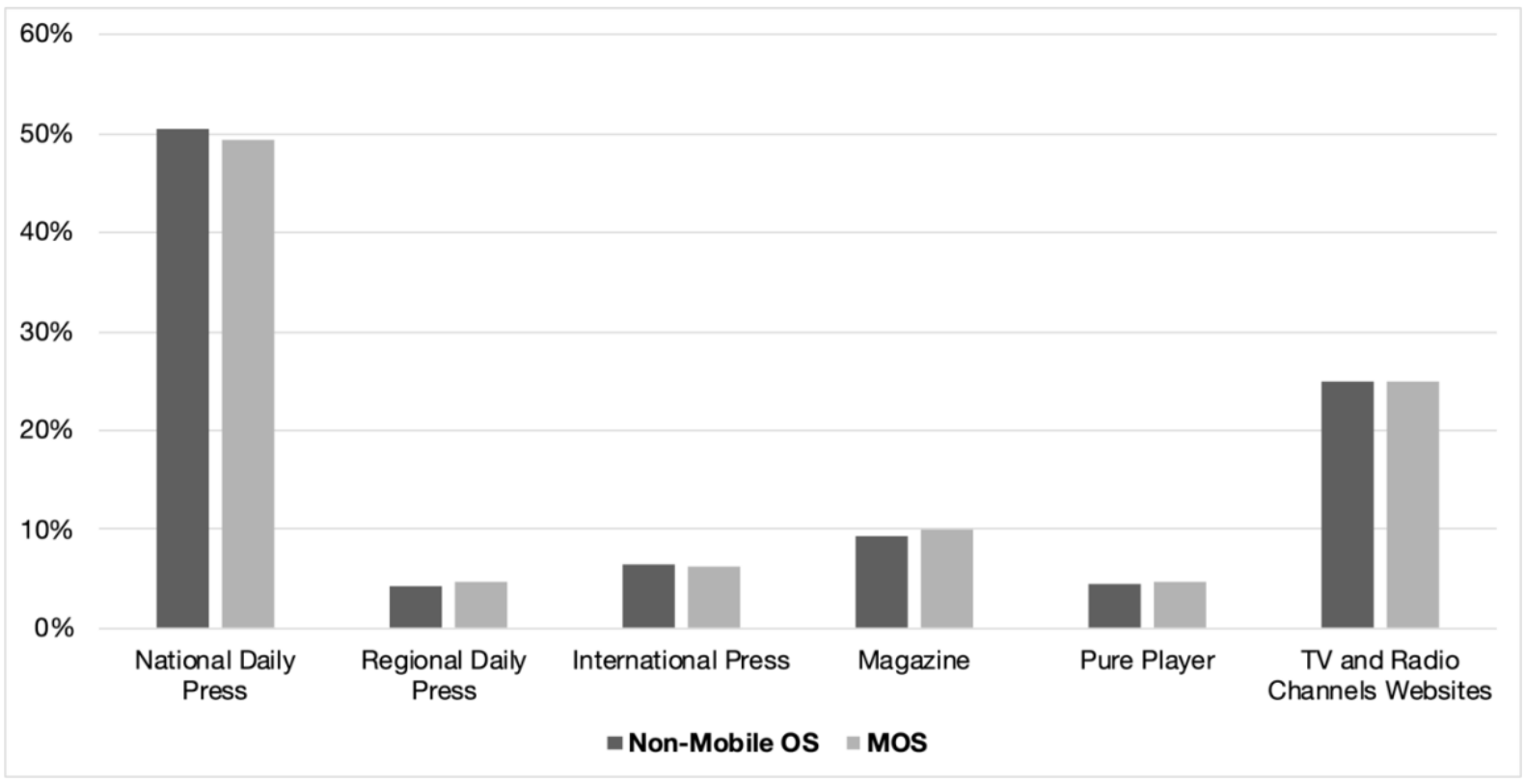

To understand why content published by professional media is less often shared through smartphones than other types of content, we should have another look at Figure 3. Indeed, it shows an over-representation of content relayed on Twitter from other social media mobile applications (10.09\%), essentially YouTube videos (69.25\%) and Facebook posts $(25.09 \%)$. Insofar as smartphones optimize interoperability between these social media outlets, notably due to the design of their notification features (Figeac and Chaulet, 2018), we can consider that they promote such content sharing between social media to a greater extent than do web browsers, whose design optimizes this interoperability to a lesser degree. The design of this interoperability can hence contribute to explain why these mobile platform users spread more contents within various social media.

Figure 3 then shows that all the instances of source-sharing other than that of "press" is slightly over-represented on MOS: partisan websites, blogs, personal pages, and so on. In particular, we note the over-representation of content libraries (Google photos, Dropbox, OneDrive, etc.) representing $2.78 \%$ (219,443 tweets) of the content shared via smartphones compared to $0.82 \%(101,447$ tweets) that was relayed via a web browser. We can consider 
their use (notably that of online photo storage) more pertinent for smartphones, since content libraries can compensate for limited storage capacity.

These results substantiate the observations made by scholars (Neudert, Howard and Kollanyi, 2019) and experts in the journalistic field (Haski, 2017) who, during the French presidential elections, identified the place held in social media by "other political news and information" sources competing with traditional media. We shall now further explore these findings by asking if this over-representation correlates with an over-representation of unreliable sources found in the content shared via smartphones.

\subsection{Twitter mobile application uses favors the sharing of unreliable sources}

Globally, reliable sources published by news professionals were clearly overrepresented in our tweet sample (cf. Table 2). This proportion, however, varies considerably from one platform to another, as the portion of unreliable sources shared via the Twitter mobile application is higher by 4.55 percentage points. The chi-square test shows a strong dependency between platform type and the reliability of information sources. And the analysis of the "adjusted residuals" confirms this finding, by revealing that Mobile OS are more correlated with the sharing of unreliable sources and Non-Mobile OS with the most reliable sources.

Table 2. Reliability of sources shared on Twitter according to platform

\begin{tabular}{|c|c|c|c|c|c|c|c|}
\hline & \multirow{2}{*}{$n$} & \multicolumn{2}{|c|}{$\%$} & \multirow{2}{*}{$\begin{array}{c}\text { Chi- } \\
\text { Square test }\end{array}$} & \multirow{2}{*}{$\begin{array}{l}\text { Cramer's } \\
\text { V test }\end{array}$} & \multicolumn{2}{|c|}{ Adjusted Residuals } \\
\hline & & Reliable & Unreliable & & & Reliable & Unreliable \\
\hline Mobile OS & $1,744,591$ & $81.88 \%$ & $18.12 \%$ & \multirow{2}{*}{$7933.9 * * *$} & \multirow{2}{*}{0,06} & -89.07 & 89.07 \\
\hline Non-Mobile OS & 564,741 & $86.43 \%$ & $13.57 \%$ & & & 89.07 & -89.07 \\
\hline
\end{tabular}

Chi-Square test: $* p<.05 ; * * p<.01 ; * * * p<.001$.

Cramer's V test: * $p<.1 ; * * p<.4 ; * * * p<.8$.

Note: "The chi-square test reveals the strong dependency between the type of platform and the reliability of information sources. The "adjusted residuals" shows that Mobile OS are more correlated with the sharing of unreliable sources and Non-Mobile OS with the most reliable sources." 
This result should be clarified with another explanatory variable in evaluating whether these observations differ from one political community to another $(\mathrm{H} 2)$. As the chi-square test shows (cf. Table 3b), the role of mobile phones in the spread of unreliable sources of information can be explained by differences between political communities. Tables $3 \mathrm{a}$ and $3 \mathrm{~b}$ show that there are wide disparities in this respect, as the Front National community shares a significantly higher number of unreliable information sources, particularly with the Twitter's mobile application. And the adjusted residuals (cf. Table 3b) confirm this trend: unreliable sources of information are widely shared by far right supporters on both platforms, Mobile OS (428,8489) and Non-Mobile OS (425,5135).

Excepting the far right, our analysis shows that the type of platform, mobile or otherwise, has almost no effect on the proportion of information, reliable or not, that is shared by the other political communities. This leads us to consider that the use of mobile phones fosters the spread of disinformation within the political communities that generally tend to share more unreliable sources. 
Table 3a. Reliability of sources shared by political communities with Mobile OS and Non-mobile OS

\begin{tabular}{|c|c|c|c|c|c|c|c|c|c|c|c|}
\hline & & \multicolumn{2}{|c|}{ LFI } & \multicolumn{2}{|c|}{ PS } & \multicolumn{2}{|c|}{ REM } & \multicolumn{2}{|c|}{ LR } & \multicolumn{2}{|c|}{ FN } \\
\hline & & $n$ & $\%$ & $n$ & $\%$ & $n$ & $\%$ & $n$ & $\%$ & $n$ & $\%$ \\
\hline \multirow[t]{2}{*}{ Mobile OS } & Reliable & \multirow{2}{*}{203,765} & $96.66 \%$ & \multirow{2}{*}{71,764} & $99.29 \%$ & \multirow{2}{*}{89,053} & $99.12 \%$ & \multirow{2}{*}{250,987} & $85.72 \%$ & \multirow{2}{*}{230,440} & $52.52 \%$ \\
\hline & Unreliable & & $3.34 \%$ & & $0.71 \%$ & & $0.88 \%$ & & $14.28 \%$ & & $47.48 \%$ \\
\hline \multirow{2}{*}{$\begin{array}{l}\text { Non- } \\
\text { mobile OS }\end{array}$} & Reliable & \multirow{2}{*}{190,356} & $97.20 \%$ & \multirow{2}{*}{97,567} & $99.46 \%$ & \multirow{2}{*}{179,463} & $99.64 \%$ & \multirow{2}{*}{465,766} & $88.81 \%$ & \multirow{2}{*}{283,905} & $62.48 \%$ \\
\hline & Unreliable & & $2.80 \%$ & & $0.54 \%$ & & $0.36 \%$ & & $11.19 \%$ & & $37.52 \%$ \\
\hline
\end{tabular}

Table 3b. Reliability of sources shared by political communities with Mobile OS and Non-mobile OS

\begin{tabular}{|c|c|c|c|c|c|c|c|c|}
\hline & & \multirow{2}{*}{$\begin{array}{c}\text { Chi-Square } \\
\text { test }\end{array}$} & \multirow{2}{*}{$\begin{array}{c}\text { Cramer's V } \\
\text { test }\end{array}$} & \multicolumn{5}{|c|}{ Adjusted Residuals } \\
\hline & & & & LFI & PS & REM & LR & FN \\
\hline \multirow[t]{2}{*}{ Mobile OS } & Reliable & \multirow{2}{*}{$198,870 * * *$} & \multirow{2}{*}{$0.4848325 * *$} & 198.87 & 126.60 & 141.26 & 59.67 & -428.85 \\
\hline & Unreliable & & & -198.87 & -126.60 & -141.26 & -59.67 & 428.85 \\
\hline \multirow{2}{*}{$\begin{array}{l}\text { Non- } \\
\text { mobile OS }\end{array}$} & Reliable & \multirow{2}{*}{$200,710 * * *$} & \multirow{2}{*}{$0.4060956^{* *}$} & 149.38 & 123.94 & 176.93 & 60.30 & -425.51 \\
\hline & Unreliable & & & -149.38 & -123.94 & -176.93 & -60.30 & 425.51 \\
\hline
\end{tabular}

Chi-Square test: * $p<.05 ; * * p<.01 ; * * * p<.001)$

Cramer's V test: * $p<.1 ; * * p<.4 ; * * * p<.8$

Note: The chi-square test reveals the strong dependency between the reliability of information sources and the political communities. The Cramer's $V$ confirms the strong dependency between these two qualitative variables. The "adjusted residuals" shows that the unreliable sources of information shared from mobile phones concern exclusively the FN (the main results are highlighted in bold). 
To fine-tune these results, we evaluated whether this over-representation of unreliable sources shared via the Twitter mobile application goes hand in hand with an overrepresentation of "other political news and information" sources (H2) (i.e. nonprofessional media). First, the chi-square test shows a strong correlation between the variables: the way different platforms (Mobile OS or Non-Mobile OS) are used to share unreliable information can be explained by the differences between political communities (cf. Table 4b). Tables $4 a$ and $4 \mathrm{~b}$ below present these results by setting aside news published by "other sources of information." These results show that the supporters of La France Insoumise (LFI; radical left) and those of the Front National (FN; far right) shared fewer articles from the "press" category than other political communities. On the other hand, members of the LFI community posted more content from social media using Mobile OS (34.17\%) and those of the FN posted more content from "other" information sources, especially via the Twitter mobile application $(42.78 \%)$. This is confirmed by the analysis of the adjusted residuals, which show a higher trend with Mobile OS (148.24) than with Non-Mobile OS (113.97). 
Table 4a. Types of ontent shared by the political communities with Mobile OS and Non-mobile OS

\begin{tabular}{|c|c|c|c|c|c|c|c|c|c|c|c|}
\hline & & \multicolumn{2}{|c|}{ LFI } & \multicolumn{2}{|c|}{ PS } & \multicolumn{2}{|c|}{ REM } & \multicolumn{2}{|c|}{ LR } & \multicolumn{2}{|c|}{ FN } \\
\hline & & $n$ & $\%$ & $n$ & $\%$ & $n$ & $\%$ & $n$ & $\%$ & $n$ & $\%$ \\
\hline \multirow[b]{2}{*}{ Mobile OS } & Social Media & & $34.17 \%$ & & $25.01 \%$ & & $10.19 \%$ & & $13.89 \%$ & & $23.77 \%$ \\
\hline & Press & 356,425 & $34.45 \%$ & 105,839 & $61.25 \%$ & 110,017 & $68.98 \%$ & 344,626 & $52.90 \%$ & 366,217 & $33.45 \%$ \\
\hline \multirow{3}{*}{$\begin{array}{l}\text { Non-mobile } \\
\text { OS }\end{array}$} & Social Media & & $24.14 \%$ & & $13.61 \%$ & & $7.20 \%$ & & $7.97 \%$ & & $18.38 \%$ \\
\hline & Press & 276,945 & $42.77 \%$ & 121,398 & $71.80 \%$ & 205,095 & $74.36 \%$ & 556,633 & $66.32 \%$ & 383,395 & $47.13 \%$ \\
\hline & Other Sources & & $33.09 \%$ & & $14.59 \%$ & & $18.43 \%$ & & $25.71 \%$ & & $34.49 \%$ \\
\hline
\end{tabular}

Table 4b. Types of content shared by the political communities with Mobile OS and Non-mobile OS

\begin{tabular}{|c|c|c|c|c|c|c|c|c|}
\hline & & \multirow{2}{*}{ Chi-Square test } & \multirow{2}{*}{ Cramer's V test } & \multicolumn{5}{|c|}{ Adjusted Residuals } \\
\hline & & & & LFI & PS & REM & LR & $\mathrm{FN}$ \\
\hline \multirow{3}{*}{ Mobile OS } & Social Media & & & 187.61 & 16.71 & -105.21 & -147.83 & 14.05 \\
\hline & Press & $114,710 * * *$ & $0.2114219 *$ & -149.43 & 117.93 & 174.49 & 122.83 & -152.37 \\
\hline & Other Sources & & & -10.01 & -139.40 & -90.10 & 2.52 & 148.24 \\
\hline \multirow{3}{*}{$\begin{array}{l}\text { Non-mobile } \\
\text { OS }\end{array}$} & Social Media & & & 174.20 & -2.01 & -92.99 & -157.70 & 94.86 \\
\hline & Press & $109,920 * * *$ & $0.1886985^{*}$ & -189.59 & 95.67 & 153.50 & 142.08 & -169.73 \\
\hline & Other Sources & & & 74.51 & -104.04 & -97.51 & -34.84 & 113.97 \\
\hline
\end{tabular}

Chi-Square test: * $p<.05 ; * * p<.01 ; * * * p<.001)$.

Cramer's V test: * $p<.1 ; * * p<.4 ; * * * p<.8$

Note: The chi-square test and the Cramer's V test reveal the dependency between the types of information sources and the political communities. The "adjusted residuals" shows, for example, that via Mobile OS, LFI tends to favor the sharing of content from others social media and to disseminate few articles from news websites. 


\section{MOBILE PHONES AND UNRELIABLE INFORMATION}

Following the first part, these results satisfy our hypotheses in demonstrating that the proportion of fairly unreliable sources circulating in a political community tends to be correlated with the proportion of "other" political information sources $(\mathrm{H} 2)$. But our results show that this overrepresentation of "other" sources, likely to be the least reliable among those shared via mobile phones, concerns only one political community: the far-right FN $\underline{\text { (cf. }}$ Table 4a). Therefore, this research shows that the participation in debates and exchanges of information via the Twitter mobile application can promote the sharing of unreliable information sources in political communities that also share the most unreliable sources from other platforms (cf. Table 4a).

\section{Discussion}

This study shows that the public debates within Twitter during the 2017 French presidential campaign were mostly based on reliable information sources produced by journalists and press agencies. As previous research demonstrates (Neudert, Howard and Kollanyi, 2019), these findings highlight the centrality of professional media in informationsharing patterns within the political communities. Our findings also highlight how mobile phones contribute to the configuration of these patterns by increasing the spread of unreliable sources in a specific way $(\mathrm{H} 1)$.

These findings should be interpreted with caution, as they show that this slight overrepresentation of mobile platforms in the spread of junk news and unreliable information concerns only one political community, the French far right political party (FN), whose candidate placed second in the election. These FN supporters generally belong to the white lower-middle class, often have a low level of education, and tend to live in suburban areas (Girard, 2017, Im et al., 2019). Many are blue-color laborers, who ordinarily access the Internet during the day via mobile devices that do not require a keyboard and mouse 
(Pasquier, 2018). It therefore appears that mobile phones seem to amplify the practices of these specific supporters, who mainly organize their debates on Twitter around a greater number of unreliable references (Gaumont, Panahi and Chavalarias, 2018).

We controlled for this over-representation: it is not related to a bias in the sample, because the proportion of users of the Twitter app in our corpus (46.99\%; cf. Table 1) is related to its proportion in the general population $\left(43.7 \%{ }^{9}\right)$; and, further, this overrepresentation of unreliable sources observed in the tweets of the FN community is all the more significant as this political community published the fewest tweets (14\%; Fraisier et al., 2018) overall during this campaign, after the PS (7\%). This overrepresentation reveals the importance of taking into account the diversity of the political communities in the study of disinformation, by showing how the disinformation phenomenon mainly concerns a "niche of disloyal groups" (Nelson and Taneja, 2018), i.e. the French far right political party (FN). By neglecting to differentiate, according to political affiliation, such practices concerning the sharing of unreliable sources on Twitter, some research tends to overlook this decisive factor of the populism on Twitter (Gil de Zúñiga, Koc Michalska and Römmele, 2020). Such consideration is all the more important because, as is shown, taking the political community into account serves to explain how mobile phones can influence human behavior in a specific way, related to the political opinions and sociological profiles of users.

To fine-tune this result, we also show that this over-representation of unreliable sources shared via the Twitter mobile application goes hand in hand with an overrepresentation of "other political news and information" sources $(\mathrm{H} 2)$, especially among the far-right community. These "non-traditional" sources are very diversified and play an important role in structuring the patterns of disinformation in France (Figeac et al., 2020;

\footnotetext{
${ }^{9}$ Médiamétrie, Audience Internet Global en France, novembre 2018. Retrieved from < https://www.mediametrie.fr/sites/default/files/2019-01/2019\%2001\%2003\%20$\% 20$ CP\%20Audience\%20Internet\%20Global_Novembre2018.pdf >
} 
Haski, 2017) and in Europe (Neudert, Howard and Kollanyi, 2019). Therefore, we emphasize the need to distinguish the types of information sources shared in social media in order to analyze the spread of unreliable sources within political communities. This helps to better understand why some Twitter communities tend to fuel their debates by sharing more unreliable sources, insofar as some of these "other" political news sources, managed by militant groups, tend to convey more disinformation.

Such distinction also helps to explain why mobile phones can contribute to the spread of unreliable information on Twitter. Indeed, these "other" political news sources are presented in a unique way within Twitter, especially those which are unreliable. Nelson and Taneja (2018) made the same observation regarding Facebook, when they showed that visitors were significantly more likely to encounter unreliable news websites by clicking a link on Facebook, especially from its mobile application. We find here the same pattern with the Twitter app, for example with the far right-wing press review website $F d e s o u c h e^{10}$, which occupies a prominent place in the French debate due to its popularity on Twitter (Caiani and Parenti, 2015); "fdesouche" is a play on words which refers to French citizens of "native stock" or blood. During the 2017 campaign, the website represented $20.32 \%$ of the unreliable references in our corpus shared from a mobile phone. Several articles were shared from Fdesouche on Twitter via the "Share" button designed in its website (cf. Figure 4). But the site is distinctive from the professional media insofar as it is specifically designed to be used mainly within the Twitter environment. The Fdesouche Twitter account presents itself as an aggregate news website, though it draws from both reliable information published by the traditional French media as well as unreliable information produced by activist websites (Figure 5a). When users view a specific headline, it is displayed as a tweet containing the URL of the original article (Figure

\footnotetext{
${ }^{10}$ Cf. http://www.fdesouche.com.
} 
5b). If they click on this URL, they are directed to the Fdesouche website (Figure 5c). As articles produced by reliable media are often secured behind a paywall, users can only read the first few lines. But they can read the entirety of articles published by unreliable sources, which favours their audience. Users are therefore encouraged to read articles from these sources in their entirety and, as a result, are more likely to share them. They are more likely to share a tweet containing fully accessible information reflecting their opinions and the ideas they wish to convey, rather than a link which instead greets users with a subscription offer. This pattern of use characteristic with respect to unreliable sources tends to lead users to share articles using the "Share" buttons presented at the end of the tweets (Figure 5b) or using the blue "TWEET" button embedded in the navigation bar of the website (Figure 5c).

Figure 4. The Twitter "Share" buttons on Fdesouche website

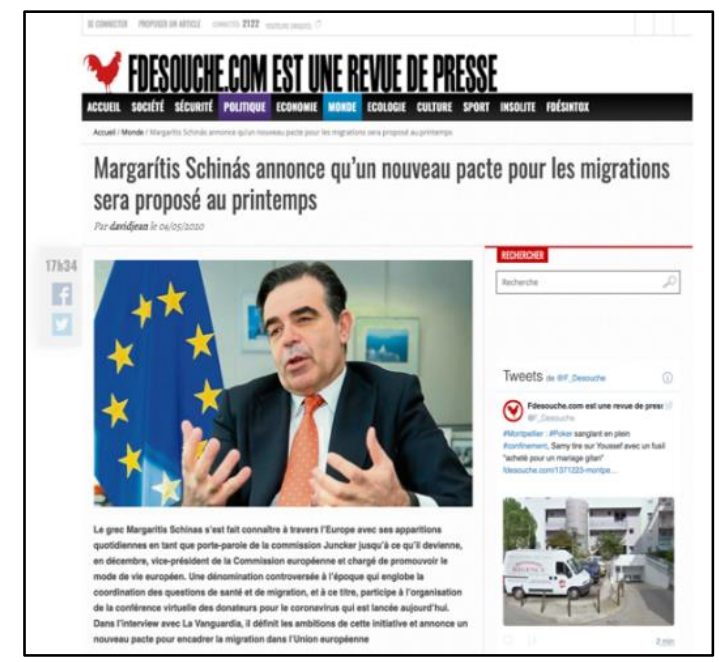


Figure 5. The information-sharing pattern of articles referenced by Fdesouche via the Twitter application

Figure 5a. The Fdesouche account on Twitter

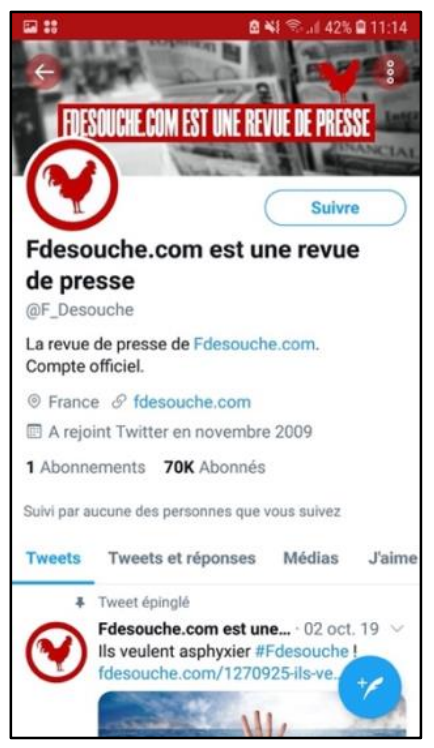

Figure 5b. Tweet with a URL to the Fdesouche website

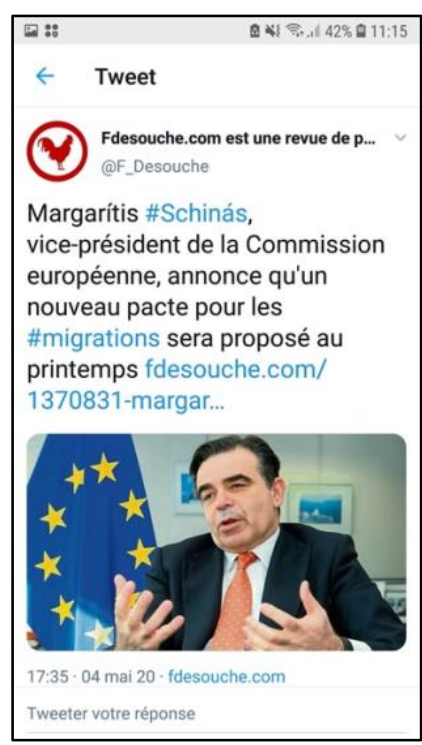

Figure 5c. Display of the Tweet button in the web browser

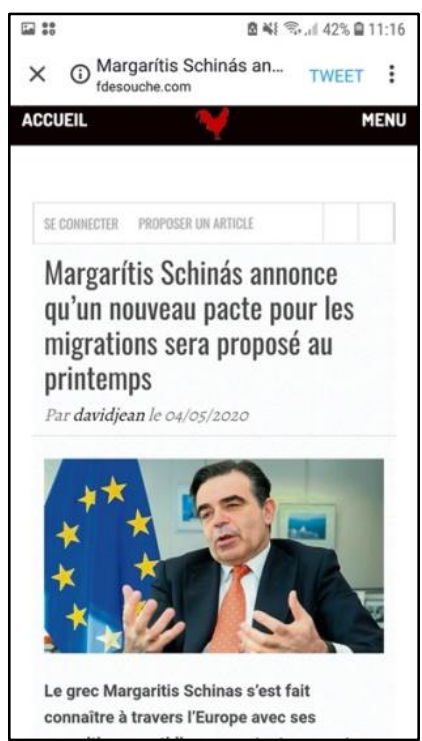

This pattern differs from French professional media apps, which essentially restrict the sharing of links to paid articles. These media are based on a commercial policy that demands the monetization of access to reliable and relevant information produced by real journalistic effort. Their Twitter accounts seek above all to attract readers to their sites, rather than to promote navigation within Twitter. By contrast, the unreliable political news websites are managed by political activists, and the financial profitability of their websites are secondary to the dissemination of "independent" and "alternative" information that competes with that produced by the professional media. That is why they tend to present "Share" buttons that are designed to lead users to share contents on Twitter. When the users read these information sources, intended to be shared on Twitter, such "Share" buttons are more conspicuous due to the small size of the screens and the embedding of the "TWEET" button in the URL (cf. Figure 5c). Such design highlights the way in which smartphone affordances can influence users' behavior and prompt them to share content on Twitter, in a way that extends Nelson and Taneja (2018) findings with respect to Facebook. 
To interpret all the consequences of these usage patterns regarding the spread of unreliable information, it is also necessary to consider how the small size of smartphones can influence users' disposition to trust information (Kim and Sundar, 2016). Even though we are analyzing here a phenomenon relating to the extreme right-wing community, it appears that these affordances of smartphones can help lead users to be manipulated into falling victim to phishing attacks (Vishwanath, 2016) or believing in fake news. That is why we are claiming here that the interoperability between the mobile design of these "other" political news sources and the social media applications helps to understand why the French far-right community shared more unreliable information from the Twitter application. Even if we insist here on this point, this article highlights more generally the complexity of this phenomenon and the diversity of the variables to be taken into account, following an interdisciplinary perspective, in order to understand the role of mobile phones in the sharing of unreliable information (e.g., the commercial policy of professional media on social media, or the size of radical political groups in a society).

We have therefore shown that these "other" political news sources, competing with professional media, play an essential role in the "fake news" crisis and in the way mobile phones can amplify the spread of unreliable information. Mobile telephony effectively favors alternative modes of citizen expression, particularly during social movements and struggles (Neumayer and Stald, 2014). It encourages a pluralism of information by further diversifying the different types of political information, as it can be identified and analyzed by scholars in different countries (Machado et al., 2018; Narayanan et al., 2019; Neudert, Howard and Kollanyi, 2019). There are now real stakes in classifying the reliability of information sources shared by citizens and political militants via mobile platforms, blogs, and applications such as Twitter. Indeed, there is a paradox: such pluralism of information, and the political participation fostered by social media and mobile phones, can amplify the spread of misinformation 
(Valenzuela et al. 2019). It becomes problematic to classify all of this wider range of information as fairly unreliable, based simply on the fact that it is not entirely produced by journalists or that its political position is too critical or counter-hegemonic. The challenge today lies in better evaluating the reliability of these alternative sources to better detect the ways in which disinformation is spread, and to determine the manner in which smartphones can promote unreliable information. If the means of expression in smartphones promote a pluralism of information, and of new forms of political participation for citizens, at what point do they offer citizens and radicalized militants a liberty of expression that is contrary to the rules of a democratic process?

\section{References:}

Benkler Y. (2006). The wealth of networks: How social production transforms markets and freedom. Yale University Press.

Boulianne, S. (2015). Social media use and participation: A meta-analysis of current research. Information, Communication \& Society, 18(5), 524-538.

Caiani, M., \& Parenti, L. (2016). European and American extreme right groups and the Internet. Routledge.

Campbell, S. W., \& Kwak, N. (2011). Mobile communication and strong network ties: Shrinking or expanding spheres of public discourse? New Media \& Society, 14(2), 262-280.

Figeac, J., \& Chaulet, J. (2018). Video-ethnography of social media apps' connection cues in public settings. Mobile Media \& Communication, 6(3), 407-427.

Figeac, J., Smyrnaios, N., Salord, T., Cabanac, G., Fraisier, O., Ratinaud, P., Seffusatti, F. (2020). Information-sharing practices on Facebook during the 2017 French presidential campaign: An "unreliable information bubble" within the extreme right. Communications, Online First, $\langle 10.1515 /$ commun-2019-0193〉.

Figueira, Á., \& Oliveira, L. (2017), « The current state of fake news: challenges and opportunities », Procedia Computer Science, 121, 817-825.

Fraisier, O., Cabanac G., Pitarch Y., Besançon R., \& Boughanem M. (2018), \#Élysée2017fr: The 2017 French Presidential Campaign on Twitter. In ICWSM 2018, June 2018, CA, United States.

Gaumont, N., Panahi, M., \& Chavalarias, D., 2018. Reconstruction of the socio-semantic dynamics of political activist Twitter networks-Method and application to the 2017 French presidential election. PLOS ONE 13, e0201879. 
Gil de Zúñiga, H., Koc Michalska, K., \& Römmele, A. (2020). Populism in the era of Twitter: How social media contextualized new insights into an old phenomenon. New Media \& Society, 22(4), 585-594.

Girard, V. (2017). Le vote FN au village. Trajectoires de ménages populaires du périurbain. Editions du Croquant.

Goode, L. (2009). Social news, citizen journalism and democracy. New Media \& Society, 11(8), 1287-1305.

Grinberg, N., Joseph, K., Friedland, L., Swire-Thompson, B., \& Lazer, D. (2019). Fake news on Twitter during the 2016 US presidential election. Science, 363(6425), 374-378.

Guess, A., Nagler, J., \& Tucker, J. (2019). Less than you think: Prevalence and predictors of fake news dissemination on Facebook. Science advances, 5(1), eaau4586.

Haski, P. (2017), Patterns of disinformation in the 2017 French Presidential Election, Report. Retrieved from https://www.bakamosocial.com/frenchelection/

Im, Z. J., Mayer, N., Palier, B., \& Rovny, J. (2019). The "losers of automation": A reservoir of votes for the radical right? Research \& Politics.

Kim, K. J., \& Sundar, S. S. (2016). Mobile persuasion: Can screen size and presentation mode make a difference to trust? Human Communication Research, 42(1), 45-70.

Koc-Michalska K, Lilleker D.G., \& Vedel T. (2016). Civic political engagement and social change in the new digital age, New Media \& Society, 18(9), 1807-1816.

Kwak, N., Campbell, S. W., Choi, J., \& Bae, S. Y. (2011). Mobile communication and public affairs engagement in Korea: An examination of non-linear relationships between mobile phone use and engagement across age groups. Asian Journal of Communication, 21(5), 485503.

Langlois, G., \& Elmer, G. (2013). The research politics of social media platforms. Culture machine, 14.

Machado, C., Kira, B., Hirsch, G., Marchal, N., Kollanyi, B., Howard, P. N., \& Barash, V. (2018). News and political information consumption in Brazil: Mapping the first round of the 2018 Brazilian presidential election on Twitter. Data Memo, 2018.4., Project on Computational Propaganda, Oxford University, UK. Retrieved from 〈http://comprop.oii.ox.ac.uk/wp-content/uploads/sites/93/2018/10/machado_et_al.pdf >

Martin, J. A. (2014). Mobile media and political participation: Defining and developing an emerging field. Mobile Media \& Communication, 2(2), 173-195.

Martin, J. A. (2015). Mobile news use and participation in elections: A bridge for the democratic divide?. Mobile Media \& Communication, 3(2), 230-249.

Narayanan, V., Kollanyi, B., Hajela, R., Barthwal, A., Marchal, N., \& Howard, P. N. (2019). News and information over Facebook and Whats App during the Indian election campaign, Data Memo, 2019.2., Project on Computational Propaganda, Oxford University, UK.

Retrieved from < http://comprop.oii.ox.ac.uk/wp-content/uploads/sites/93/2019/05/Indiamemo.pdf >

Nelson, J. L., \& Taneja, H. (2018). The small, disloyal fake news audience: The role of audience availability in fake news consumption. New Media \& Society, 20(10), 3720-3737. 
Neudert, L. M., Howard, P., \& Kollanyi, B. (2019). Sourcing and automation of political news and information during three European elections. Social Media+ Society, 5(3), 2056305119863147.

Neumayer, C., \& Stald, G. (2014). The mobile phone in street protest: Texting, tweeting, tracking, and tracing. Mobile Media \& Communication, 2(2), 117-133.

Pasquier, D. (2018). Classes populaires en ligne : des « oubliés » de la recherche? Réseaux, 208-209(2), 9-23.

Shane P. M. (Ed.). (2004). Democracy online: the prospects for political renewal through the Internet. Routledge.

Smith, A., \& Page, D. (2015). U.S. smartphone use in 2015. Retrieved from http://www.pewinternet.org/2015/04/01/us-smartphone-use-in-2015/

Smyrnaios, N., \& Ratinaud, P. (2017). The Charlie Hebdo attacks on Twitter: A comparative analysis of a political controversy in English and French. Social Media+ Society, 3(1).

Tandoc Jr, E. C., Lim, Z. W., \& Ling, R. (2018). Defining “fake news" A typology of scholarly definitions. Digital journalism, 6(2), 137-153.

Tufekci, Z. (2017). Twitter and tear gas: The power and fragility of networked protest. Yale University Press.

Valenzuela, S., Halpern, D., Katz, J. E., \& Miranda, J. P. (2019). The Paradox of Participation Versus Misinformation: Social Media, Political Engagement, and the Spread of Misinformation. Digital Journalism, 7(6), 802-823.

Vishwanath, A. (2016). Mobile device affordance: Explicating how smartphones influence the outcome of phishing attacks. Computers in Human Behavior, 63, 198-207.

Vosoughi, S., Roy, D., \& Aral, S. (2018). The spread of true and false news online. Science, 359(6380), 1146-1151.

Weedon, J., Nuland, W., \& Stamos, A. (2017). Information operations and Facebook. Retrieved from Facebook:

https://fbnewsroomus.files.wordpress.com/2017/04/facebook-and-information-operationsv1.pdf

Westlund, O. (2015). News consumption in an age of mobile media: Patterns, people, place, and participation. Mobile Media \& Communication, 3(2), 151-159. 